\title{
Estudio de la teoría del delito en el Código Orgánico Integral Penal.
}

Study of the theory of crime in Criminal Law

\author{
Wilson Pacheco Almeida* \\ Investigador Jurídico Independiente
}

Infomación del Artículo

Original - Ruptura, 2020

Artículo recibido / Received: 3 de octubre, 2020

Artículo aceptado / Accepted: 8 de diciembre, 2020

\section{Citación}

Pacheco, W. (2020). Estudio de la teoriía del delito en el Código Orgánico Integral Penal. Revista Ruptura de la Asociación Escuela de Derecho de la PUCE. Edición 2020, p. (477-512).

DOI: $10.26807 /$ rr.vi02.28

Resumen: El estudio de la dogmática penal es de vital importancia en un estudiante de derecho y mucho más si en un futuro tiene pensado ejercer la profesión en la rama del Derecho Penal, ya que la misma es fundamental para la construcción de una teoría del caso, ya sea para la parte que acusa (Fiscalía), como para la defensa. A través de un análisis minucioso de los elementos que componen la teoría del delito, se puede encontrar una peculiaridad que sea determinante para que el abogado defensor obtenga un dictamen favorable para el procesado en un litigio, o de igual manera, que se determine su responsabilidad penal. Es por eso, que el Código Orgánico Integral Penal (COIP) reformado recoge temas dogmáticos

* Estudiante de la carrera de Derecho, Facultad de Jurisprudencia, Ciencias Políticas y Económicas de la Universidad Tecnológica Indoamérica, campus Quito. Correo: alexispa10@hotmail.com. 
tales como: el concepto de dolo, el error de tipo, error de prohibición, por nombrar algunos. Es decir, instituciones dogmáticas que sin duda son importantes en la praxis jurídica.

Palabras clave: Teoría, dogmática, delito, tipicidad, antijuridicidad, culpabilidad.

Abstract: The study of criminal dogmatics is very important in a law student, also if in the future plans to work in Criminal Law, so, this is fundamental for the construction of a theory of the case, either for the accusing party (Prosecutor), or for the defense lawyer. Since through a careful analysis of the elements of the theory of crime, you can find a peculiarity that is decisive to be able to obtain a judgment in favor of our client. That is why the reformed Organic Criminal Code (COIP) includes dogmatic themes such as the concept of malice, type error, prohibition error, etc. So, dogmatic institutions are undoubtedly are importance in legal practice.

Keywords: Theory, dogmatic, crime, tipicality, unlawfulness, guiltiness.

\section{Introducción}

El presente trabajo académico va a abordar un análisis de la teoría dogmática del delito y como la misma está inmersa en nuestro Código Orgánico Integral Penal. Este cambio es significativamente importante para aplicarlo en el desarrollo de casos prácticos y de esta manera evitar confusiones o choques teóricos dogmáticos entre operadores de justicia, fiscales y abogados defensores.

Cuando se habla de teoría del delito, inmediatamente se proyecta en la cabeza sus principales precursores que desde 1906 han venido dando forma a la misma, estos son: Von Liszt, Beling, Mezger, Mayer, Welzel, entre otros. Y pues, junto con ellos se han venido desarrollando las diferentes escuelas como: la escuela clásica, neoclásica, finalista y hoy en día aún en desarrollo la escuela funcionalista, que tiene como principales exponentes a los maestros Claus Roxín con su funcionalismo moderado; y por otro lado, al genio Günther Jakobs 
con su funcionalismo radical. Ahora, para entrar en materia se debe plantear la siguiente pregunta: ¿Cuál es la escuela de la dogmática penal adoptada en el COIP?

Para la realización del presente trabajo, el autor se ha apoyado en el Código Orgánico Integral Penal, en la doctrina penal tanto nacional como internacional, y en la experiencia propia como estudiante de derecho, es por eso que, el trabajo realizado con el mayor esmero y pasión, tiene como finalidad contribuir a la cultura jurídica del país y despertar el interés de estudiar esta bonita rama del derecho como lo es el Derecho Penal.

\section{Categoría dogmática de la conducta}

\subsection{Conceptualización de acción}

Para iniciar con el estudio de la teoría del delito, debemos tener claro que para que se configure una infracción penal como tal, está primero debe aprobar todas las categorías dogmáticas del delito, constituido por: conducta (acción u omisión), tipicidad, antijuridicidad y culpabilidad. Siendo así, se debe verificar el cumplimiento en estricto sentido de cada uno de estos peldaños dogmáticos mencionados anteriormente, puesto que, en caso de que uno de ellos no se configure o ya sea el caso, exista una causa de justificación, no se cumpla los elementos objetivos del tipo o alguna causa de exclusión de la antijuridicidad o culpabilidad, la conducta ejercida por un sujeto no puede ser objeto de consecuencia jurídica.

Empezando ya con el estudio de la teoría del delito y su presencia en el Código Orgánico Integral Penal (en adelante llamado COIP), debemos en primer lugar hablar sobre la categoría dogmática de la conducta.

En el presente peldaño dogmático se encuentra tanto la acción y la omisión que realiza una persona (recordar que el Derecho Penal sanciona conductas realizadas por el ser humano), al hablar de acción 
se debe tener en cuenta que el concepto de la misma ha sido objeto de variaciones a lo largo del tiempo, definiéndola desde la escuela clásica como la modificación voluntaria del mundo exterior perceptible por los sentidos (Von Listz, 1927, p.297); mientas que, para los finalistas se define a la acción como esa modificación voluntaria del mundo exterior perceptible por los sentidos que prevé un resultado final. Es decir, al momento de que una persona realiza un acto, esta ya tiene una proyección futura en su cabeza del resultado que va a causar, es por eso que, el acto voluntario debe prever el resultado (Rodríguez, 2019, p.49).

El COIP en su libro primero, artículo 18 establece el concepto de infracción penal y dice: "Es la conducta típica, antijurídica y culpable, cuya sanción se encuentra prevista en este Código" (COIP, 2014). A través del presente artículo, se constata que la normativa penal vigente en el Ecuador sí, reconoce criterios dogmáticos, al establecer que estamos frente a una infracción penal cuando se verifique el cumplimiento en estricto orden de la teoría del delito, y que aquella es objeto de consecuencia jurídica establecida en el mismo código. Otro tema que trata el presente artículo es el de la imposición de una sanción, esto es muy importante y se debe tener muy claro, ya que al hablar de la estructura del tipo penal, éste debe seguir la siguiente composición: descripción de una conducta (supuesto fáctico), más la consecuencia jurídica, ya que si solamente tiene la descripción de un supuesto de hecho y no establece una sanción a la misma, se estaría frente a una mera recomendación. (Rodríguez, 2019).

Ahora, se debe tener claro cuando estamos frente a una conducta penalmente relevante y para lo cual el COIP en el inciso primero del artículo 22 señala: "Son penalmente relevantes las acciones $\mathrm{u}$ omisiones que ponen en peligro o producen resultados lesivos, descriptibles y demostrables". (COIP, 2014). Estas acciones u omisiones que describe la norma deben contrariar al derecho, a la norma positiva vigente en el ordenamiento jurídico nacional o internacional del cual el Estado sea parte. Otra peculiaridad que establece el presente artículo es su inciso segundo el cual establece que: "No se podrá sancionar a una persona por cuestiones de identidad, peligrosidad o características personales". (COIP, 2014). El presente 
inciso hace referencia a lo que en la dogmática se conoce como el "derecho penal del enemigo" establecido por el ilustre maestro Günther Jakobs, mismo que por disposición expresa en la norma constitucional $^{1}$ es totalmente inaplicable aquí en el Ecuador, ya que como se conoce en el Ecuador se maneja un derecho penal de acto y no ante un derecho penal de autor.

\subsection{La omisión}

En cuanto a la omisión, el mismo texto normativo en el inciso segundo de su artículo 23 indica que: "No impedir un acontecimiento, cuando se tiene la obligación jurídica de impedirlo, equivale a ocasionarlo" (COIP, 2014). En palabras de Muñoz Conde, el delito omisivo consiste siempre, por tanto, en la omisión de una determinada acción que el sujeto tenía obligación de realizar y que podía realizar (Muñoz Conde, 2010, p.239). Siguiendo estos lineamientos, la doctrina dominante reconoce dos tipos de omisión, tales como: omisión propia (pura) y omisión impropia (comisión por omisión). Antes de pasar a ver estas formas de omisión, se debe tener en cuenta que en el Ecuador se maneja un sistema de numurus clausus.

1 CRE - Art. 11.2.- Nadie podrá ser discriminado por razones de etnia, lugar de nacimiento, edad, sexo, identidad de género, identidad cultural, estado civil, idioma, religión, ideología, filiación política, pasado judicial, condición socio-económica, condición migratoria, orientación sexual, estado de salud, portar VIH, discapacidad, diferencia física; ni por cualquier otra distinción, personal o colectiva, temporal o permanente, que tenga por objeto o resultado menoscabar o anular el reconocimiento, goce o ejercicio de los derechos. La ley sancionará toda forma de discriminación. El Estado adoptará medidas de acción afirmativa que promuevan la igualdad real en favor de los titulares de derechos que se encuentren en situación de desigualdad. 


\subsubsection{Omisión Propia}

En primer lugar, se tiene a la omisión propia (pura) que no es más que aquel no hacer que una persona común y corriente podía realizar para evitar un resultado material típico, así también, este tipo de omisión se encuentra reglado en la normativa penal ecuatoriana y que por su naturaleza en la mayoría de veces inician de la siguiente manera "el que omita..." como por ejemplo: la omisión de denuncia ${ }^{2}$. En este tipo de omisión se sanciona a la persona por su no actuar ante una situación, más no se le sanciona por el resultado típico que deriva del mismo.

Esto es, porque en este tipo de omisión no existe una posición de garante otorgada por la ley, por un contrato o por su actuar precedente, entre el sujeto que omitió realizar cierta acción y el bien jurídico que se vulneró. Por lo tanto, se establece un deber de mínima solidaridad del sujeto que omitió realizar cierta acción, este deber de mínima solidaridad refiere a esa forma de actuación que la sociedad espera de cierta persona por su condición de ciudadano, para tener una convivencia en armonía.

\subsubsection{Omisión Impropia}

Respecto a la omisión impropia o también llamada comisión por omisión se debe empezar revisando como la define textualmente el COIP, que en su artículo 28 establece que:

La omisión dolosa describe el comportamiento de una persona que, deliberadamente, prefiere no evitar un resultado material típico, cuando se encuentra en posición de garante.

2 COIP - Art 277. - Omisión de denuncia. - [...] la persona que en calidad de servidora o servidor público y en función de su cargo, conozca de algún hecho que pueda configurar una infracción penal y no lo ponga inmediatamente en conocimiento de la autoridad, será sancionada con pena privativa de libertad de quince a treinta días. 
Se encuentra en posición de garante la persona que tiene una obligación legal o contractual de cuidado o custodia de la vida, salud, libertad e integridad personal del titular del bien jurídico y ha provocado o incrementado precedentemente un riesgo que resulte determinante en la afectación de un bien jurídico. (COIP, 2014).

Como se puede observar en este tipo de omisión si existe una posición de garante, que no es más que esa relación de cuidado que una persona tiene en relación con otra, por lo tanto, tiene a su cargo el proteger y velar por el bien jurídico protegido de aquella persona. Es por eso que, a diferencia de la omisión propia y su deber de mínima solidaridad, en este tipo de omisión se tiene presente un deber de máxima solidaridad, y por lo mismo, en caso de faltar a este la persona responsable responde por el resultado material típico producido por su inobservancia.

\subsection{Causas de exclusión de la conducta}

Antes de finalizar el estudio de la categoría dogmática de la conducta y pasar a estudiar la tipicidad, se debe analizar las causas de exclusión de la misma, que el COIP las recoge en su libro preliminar parte gene$\mathrm{ral}^{3} \mathrm{y}$ que a lo largo del desarrollo de la doctrina se han clasificado en tres principales que son: i) Fuerza física irresistible; ii) Movimiento reflejo; y iii) Estado de plena inconciencia. Los cuales deben ser debidamente comprobados por quien los alega, esto significa que la carga probatoria se invierte, también llamada carga dinámica de la prueba.

\subsubsection{Fuerza física irresistible}

La fuerza física irresistible se refiere a esa fuerza proveniente del exterior, misma que por su naturaleza no puede ser prevenida o resistida por el sujeto que la sufre, por lo tanto, por las características

3 COIP - Art 24. - Causas de exclusión de la conducta. - No son penalmente relevantes los resultados dañosos o peligrosos resultantes de fuerza física irresistible, movimientos reflejos o estados de plena inconciencia, debidamente comprobados. 
mencionadas anteriormente, el sujeto objeto de esta fuerza exterior pasa a ser cosificado, es decir, no tiene control sobre su cuerpo y sus acciones, por ejemplo:

Ejemplo A: Juan está fuera de una tienda observando unas zapatillas marca Nike que le gustaron, ese día, en el centro comercial en el que se encontraba estaba un artista famoso de la ciudad de Quito, por lo que, al enterarse de aquello, una multitud eufórica corre por el centro comercial en busca de una foto con dicho personaje, es ahí cuando esta multitud pasa por el pasillo en el que se encontraba Juan, lo empujan fuertemente y este al estrellarse con el vidrio del local que estaba enfrente, lo rompe cayendo dentro del local y ocasionando daños materiales. Pregunta: ¿ Juan responde por el delito de daño a bien ajeno ${ }^{4}$ ? No, puesto que la conducta de Juan estaría justificada por tratarse de fuerza física irresistible, es decir, de una causa de justificación de la conducta, obviamente se debe comprobar por parte de quien lo alega (defensor público o privado), quedando así exento de responsabilidad penal.

\subsubsection{Movimiento reflejo}

Referente al movimiento reflejo, Polaino Navarrete, citado por Rodríguez Moreno, (2019) menciona que se tratan de los movimientos corporales en los que por excitación de los nervios motores de la persona, ésta no se encuentra bajo influjo anímico, sino que los movimientos corporales son inmediatamente desencadenados por un estímulo fisiológico corporal. A diferencia de la fuerza física irresistible, el movimiento reflejo proviene del interior de la persona, causando una desconexión de los nervios motores, pasando así la persona a no tener control sobre su accionar en el momento, por ejemplo:

4 COIP - Art 204. - Daño a bien ajeno. - La persona que destruya, inutilice o menoscabe un bien ajeno será sancionada con pena privativa de libertad de dos a seis meses. 
Ejemplo B: Marco, un chico universitario, introvertido, tímido camina de regreso a su casa después de un día largo de clases, al transitar por un pasillo oscuro que utiliza para acortar camino y llegar más pronto a su casa, Pedro al ver que Marco viene caminando decide esconderse detrás de los tachos de basura para jugarle una broma, en el momento en que Marco está pasando por ahí, Pedro sale desprevenidamente y lo asusta, por lo que, Marco en un acto de reacción por alteración de sus nervios motores, suelta un golpe en el rostro de Pedro y sale corriendo. Resulta que producto de dicho golpe, Pedro sufre lesiones en su nariz. Pregunta: ¿2Responde Marco por el delito de lesiones ${ }^{5}$ ocasionadas a Pedro? No, puesto que Marco actuó por una reacción ocasionada por la alteración de sus nervios motores internos, por ende, actúa bajo movimiento reflejo. De esta manera se justifica el accionar de Marco, quedando exento de cualquier responsabilidad penal.

\subsubsection{Estado de plena inconciencia}

Como última causa de justificación de la conducta existe el estado de plena inconsciencia, y una de las principales características para que se configure el mismo, es que, debe ser un estado de plena inconciencia momentáneo, ya que si fuera permanente se trataría de un sujeto inimputable y esto se analiza ya en la última categoría dogmática, llamada culpabilidad. Otra característica importante del estado de plena inconciencia es que no debe ser auto provocado por el sujeto que ejerza la conducta, es decir, si una persona tiene por objetivo robar un banco y para ello procede a ingerir cantidades extremas de alcohol, inhalar sustancias catalogadas sujetas a fiscalización o preparados que las contengan, entro otros, para estar bajo efectos nocivos y así pretender justificar su accionar, sería totalmente inadmisible y por ende, sí respondería penalmente.

5 COIP - Art 152. 2. - Lesiones. - La persona que lesione a otra será sancionada de acuerdo con las siguientes reglas: 2 . Si produce a la víctima un daño, incapacidad o enfermedad de nueve a treinta días, será sancionada con pena privativa de libertad de dos meses a un año. 


\section{Tipicidad}

Una vez analizada y cumplida la primera categoría dogmática del delito, se tiene que pasar a desarrollar todo lo relacionado a la tipicidad, que no es más que esta subsunción de la conducta realizada por un sujeto al tipo penal descrito en la norma. Por lo tanto, es una categoría muy importante dentro del esquema del delito, ya que mediante el análisis sistemático de los elementos objetivos como subjetivos se puede saber si una persona se encuentra frente a una conducta típica o no. El COIP en el artículo 25 establece lo que se entiende por tipicidad y dice: "Los tipos penales describen elementos de las conductas penalmente relevantes" (COIP, 2014).

La tipicidad anteriormente era una categoría dogmática netamente objetiva y que con el paso del tiempo y el estudio de importantes del derecho penal, existe hoy en día una tipicidad tanto objetiva, como subjetiva. Dentro de la tipicidad objetiva se tiene una serie de elementos sumamente importantes para que se pueda configurar la misma, ya que si uno de ellos no se puede hablar de una conducta penalmente relevante, estos elementos constitutivos de la tipicidad objetiva son: i) sujeto activo; ii) sujeto pasivo; iii) bien jurídico protegido; iv) verbo rector; v) objeto material y vi) elemento normativo; por otro lado, en la tipicidad subjetiva se estudia la intencionalidad del sujeto activo al momento de realizar cierta conducta, por lo que, aquí se verifica si el sujeto activo al momento de realizar la acción u omisión lo hizo con: i) dolo o ii) culpa.

\subsection{Tipicidad Objetiva}

Como se mencionó anteriormente, en la tipicidad objetiva existen varios elementos constitutivos de la misma, puesto que, a falta de uno de ellos no se configuraría la categoría dogmática de la tipicidad, ergo, no podríamos seguir realizando el estudio de la teoría del delito, y de esta manera estar frente a una conducta atípica y penalmente irrelevante realizada por un sujeto. Dicho lo anterior, toca estudiar cada uno de estos elementos más detenidamente. 


\subsubsection{Sujeto activo}

Sujeto activo es la persona natural o jurídica que realiza u omite cierta acción con la finalidad de cometer una infracción penal para poder conseguir un resultado final. Dentro del estudio del sujeto activo se encuentra una subclasificación, ya que existen tipos penales que pueden ser cometidos por sujetos activos calificados y tipos penales que pueden ser cometidos por sujetos activos sin alguna determinación específica.

\subsubsection{Sujeto activo calificado}

Para empezar a estudiar este sujeto activo calificado, también conocido como sujeto activo determinado, nominado o cualificado, debemos partir de la idea de que existen delitos comunes y especiales, y son específicamente este tipo de delitos especiales los que requieren de un sujeto con determinadas características para que puedan ser cometidos. Dichas características son dadas por ejemplo por cuestiones laborales, como una persona que trabaja dentro del sector público, obtiene esta característica de funcionario público; así también, podemos hablar de características especiales en aquellas personas que han dedicado su vida al ejercicio de la defensa nacional, en instituciones como la Policía Nacional o las Fuerzas Armadas del Ecuador, incluso una persona puede estar revestido de esta característica especial al momento de cumplir la mayoría de edad (18 años), etc.

Entonces, son sujetos activos calificados aquellas personas que por sus características especiales son proclives al cometimiento de ciertos delitos especiales establecidos en la norma penal, a continuación un ejemplo:

Ejemplo C: Roberto, es un aclamado fiscal de la provincia de Pichincha, que se encuentra llevando una investigación previa por un supuesto delito de hurto ${ }^{6}$, un día llega el defensor público del señor

6 COIP - Art 196. - Hurto. - La persona que sin ejercer violencia, amenaza o intimidación en la persona o fuerza en las cosas, se apodere ilegítimamente 
investigado a hablar con el fiscal Roberto sobre la investigación, es ahí, cuando Roberto le dice que si le entrega USD 1000 dólares, el se abstiene de seguir investigando, aplicando el principio de oportuni$\mathrm{dad}^{7}$ establecido en el COIP.

Entonces, el defensor público de inmediato procede a denunciar el hecho ante la autoridad competente. Pregunta: ¿Roberto, cometió un delito? Sí, estaría subsumido su conducta al delito de concusión $^{8}$ por abusar de su cargo para exigir gratificaciones no debidas a otra persona.

\subsubsection{Sujeto activo no calificado}

El sujeto activo no calificado, también conocido como indeterminado o innominado es cualquier persona natural o jurídica imputable que no tenga o requiera de caracteristicas específicas para que le sea imputable un delito. La mayoría de delitos que encontramos en el COIP, son delitos simples, es decir, los puede cometer cualquier

de cosa mueble ajena, será sancionada con pena privativa de libertad de seis meses a dos años.

7 COIP - Art 412.1. - Principio de oportunidad. - La o el fiscal podrá abstenerse de iniciar la investigación penal o desistir de la ya iniciada, en los siguientes casos: 1 . Cuando se trate de una infracción penal sancionada con pena privativa de libertad de hasta cinco años, con excepción de las infracciones que comprometen gravemente el interés público y no vulneran a los intereses del Estado.

8 COIP - Art 281. - Concusión. - Las o los servidores públicos y las personas que actúen en virtud de una potestad estatal en alguna de las instituciones del Estado, determinadas en la Constitución de la República, sus agentes o dependientes oficiales que abusando de su cargo o funciones, por sí o por medio de terceros, ordenen o exijan la entrega de derechos, cuotas, contribuciones, rentas, intereses, sueldos o gratificaciones no debidas, serán sancionadas con pena privativa de libertad de tres a cinco años. 
persona, ejemplo de aquello: Homicidio ${ }^{9}$, Robo $^{10}$, Hurto, Intimidación ${ }^{11}$, por nombrar algunos.

\subsubsection{Sujeto pasivo}

El sujeto pasivo es aquella persona natural o jurídica sobre la cual recae cierta conducta realizada por el sujeto activo. La mayoría de las veces que se escuche sujeto pasivo, se debe venir a la cabeza la idea de la víctima y no está mal, pero se debe saber que no en todos los casos la víctima es específicamente el sujeto pasivo, puesto que existen delitos en donde la persona que es objeto de una conducta antijurídica ejercida por el sujeto activo, afecta a una tercera la cual viene a tener el rol de víctima, como por ejemplo:

Ejemplo D: Marcelo es un joven tímido de 20 años, que no socializa mucho y pasa frecuentemente en su casa. Frente a la casa de Marcelo viven sus vecinos María y Pedro, quienes tienen una hija de 12 años de edad. Un día Marcelo, intenta entablar una conversación con ella, pero ella lo rechaza. Marcelo toma este rechazo muy mal, por lo que en la noche procede a irrumpir en la propiedad privada de sus vecinos, entra a la habitación de la niña para proceder mediante intimidación y amenazas a introducir su miembro viríl

9 COIP - Art 144. - Homicidio. - La persona que mate a otra será sancionada con pena privativa de libertad de diez a trece años.

10 COIP - Art 189. - Robo. - La persona que mediante amenazas o violencias sustraiga o se apodere de cosa mueble ajena, sea que la violencia tenga lugar antes del acto para facilitarlo, en el momento de cometerlo o después de cometido para procurar impunidad, será sancionada con pena privativa de libertad de cinco a siete años.

11 COIP - Art 154. - Intimidación. - La persona que amenace o intimide a otra con causar un daño que constituya delito a ella, a su familia, a personas con las que esté íntimamente vinculada, siempre que, por antecedentes aparezca verosímil la consumación del hecho, será sancionada con pena privativa de libertad de uno a tres años. 
de manera completa en la cavidad vaginal de la menor, es decir, comete el delito de violación ${ }^{12}$.

En el ejemplo anteriormente expuesto, el sujeto pasivo de la acción es la niña de 12 años, puesto que la conducta ejercida por el sujeto activo (Marcelo) recae sobre ella. Pero, en este caso la víctima de tal suceso viene a ser también los padres de la menor de edad. Ahora, con el presente ejemplo se puede constatar que existe también sujeto pasivo calificado, ya que al revisar el numeral 3 del artículo 171, se habla de que es violación cuando la víctima sea menor de 14 años, es decir, este númeral dota de una condición específica al sujeto pasivo de este delito, considerándose como sujeto pasivo calificado.

\subsubsection{Bien jurídico}

A continuación, respecto al bien jurídico protegido, se debe partir estableciendo que es un derecho fundamental de relevancia social. Polaino Navarrete citado en Rodríguez (2019) denomina al bien jurídico protegido como todo valor normativamente evaluado y estimado como digno, merecedor y necesitado de la máxima protección jurídica (p.136). Así también, se debe tener bien claro que todo bien jurídico es un derecho, pero no todo derecho es un bien jurídico, pues como se citó anteriormente, se realiza una evaluación al derecho para ver si es objeto de máxima protección jurídica o no, pues estos deben ser de relevancia social.

Al respecto, Muñoz Conde (2010) establece que los bienes jurídicos son aquellos presupuestos que la persona necesita para su autorrealización y desarrollo de su personalidad en la vida social (p.59).

12 COIP - Art 171. - Violación. - Es violación el acceso carnal, con introducción total o parcial del miembro viril, por vía oral, anal o vaginal; o la introducción, por vía vaginal o anal, de objetos, dedos u órganos distintos al miembro viril, a una persona de cualquier sexo. Quien la comete, será sancionado con pena privativa de libertad de diecinueve a veintidós años en cualquiera de los siguientes casos: 3 . Cuando la víctima sea menor de catorce años. 
La normativa tiene como objetivo la protección y defensa de estos bienes jurídicos protegidos que posee cada persona para buscar su realización social, como por ejemplo: en el asesinato, el bien jurídico es "vida"; en el robo es la "propiedad"; en el delito de violación es la "integridad y libertad sexual"; en el delito de cohecho es la "eficiencia de la administración pública". Entonces, se puede concluir que absolutamente todos los tipos penales en sus descripciones buscan la no vulneración, lesión o puesta en peligro de estos valores a través de mandatos o prohibiciones dirigidas a la sociedad.

\subsubsection{Verbo rector}

Es aquel verbo que describe la conducta que una persona debe realizar u omitir para que se ajuste al tipo penal. El verbo rector es sumamente importante ya que con el mismo se puede diferenciar un tipo penal de otro. No está por demás decir, pero el verbo rector siempre va a estar descrito en el tipo penal, por ejemplo: en el delito de homicidio el verbo rector es "matar"; en el robo el verbo rector es "sustraer".

Así mismo, siguiendo las palabras y el pensamiento de Muñoz Conde (2010), claramente establece que la configuración y redacción de tipos penales, deben ser lo más simples posibles, usando un lenguaje claro, empleando sobre todo elementos lingüísticos descriptivos que cualquier persona común y corriente pueda entender y apreciar de la mejor manera (p.256).

\subsubsection{Objeto material}

Al momento de referirse al objeto material, no se debe confundir nunca con el sujeto pasivo, ya que existen ciertas confusiones al momento de hablar sobre quién y sobre qué recae la conducta. Estas son pequeñas confusiones que no se deben dar. Por eso, al hablar del objeto material, se hace referencia a la cosa, objeto, bien mueble o inmueble sobre el que recae de manera directa la acción u omisión ejercida por el sujeto activo. 
Muñoz Conde, con su experiencia de siempre dice que objeto material es:

\begin{abstract}
Aquella cosa del mundo exterior sobre la que recae directamente la acción típica (por ejemplo: la cosa mueble ajena en el hurto) y que en los delitos de resultado suele ser destruida o al menos puesta en peligro (por ejemplo: la cosa dañada en el delito de daños; la vida puesta en peligro en un delito de conducción temeraria de un vehículo a motor). (Muñoz Conde \& García, 2010).
\end{abstract}

\title{
2.1.6. Elemento normativo
}

Es aquella redacción normativa y descriptiva de los tipos penales, mediante el cual al leer la norma se puede verificar qué se necesita para que el verbo rector esté ejecutado o frente a qué delito se estaría, porque a través de esta redacción se puede diferenciar un delito de otro.

Este elemento normativo que a su vez viene a ser objetivo, es el que permite que un delito con igual verbo rector y el mismo bien jurídico protegido (Rodríguez, 2019, p.178), sea diferente el uno del otro, pues en la propia redacción del tipo se encuentran elementos diferenciadores, por ejemplo: en el delito de homicidio y asesinato.

Art 144. - Homicidio. - La persona que mate a otra será sancionada con pena privativa de libertad de diez a trece años. (COIP, 2014).

Art 140. - Asesinato. - La persona que mate a otra será sancionada con pena privativa de libertad de veintidós a veintiséis años, si concurre alguna de las siguientes circunstancias:

1. A sabiendas, la persona infractora ha dado muerte a su ascendiente, descendiente, cónyuge, conviviente, hermana o hermano.

2. Colocar a la víctima en situación de indefensión, inferioridad o aprovecharse de esta situación. 
3. Por medio de inundación, envenenamiento, incendio o cualquier otro medio se pone en peligro la vida o la salud de otras personas

4. Buscar con dicho propósito, la noche o el despoblado.

5. Utilizar medio o medios capaces de causar grandes estragos.

6. Aumentar deliberada e inhumanamente el dolor a la víctima.

7. Preparar, facilitar, consumar u ocultar otra infracción.

8. Asegurar los resultados o impunidad de otra infracción.

9. Si la muerte se produce durante concentraciones masivas, tumulto, conmoción popular, evento deportivo o calamidad pública.

10. Perpetrar el acto en contra de una o un dignatario o candidato a elección popular, elementos de las Fuerzas Armadas o la Policía Nacional, fiscales, jueces o miembros de la Función Judicial por asuntos relacionados con sus funciones o testigo protegido. (COIP, 2014).

Al dar lectura de los presentes tipos penales, se da cuenta que en efecto, ambos protegen el mismo bien jurídico protegido (vida) y que de igual manera el verbo rector en ambos es el mismo (matar), pero ¿Qué diferencia el uno del otro? ¿Cuándo saber que se está frente a un homicidio o a un asesinato? Simplemente se debe leer el numeral primero del artículo 140 asesinato. Claramente dice: 1. A sabiendas, que la persona infractora ha dado muerte a su ascendiente, descendiente, cónyuge, conviviente, hermana o hermano. Entonces, no es lo mismo que Juan Pérez mate a una persona que no conocía, que el mismo Juan Pérez mate a su esposa (cónyuge), son dos tipos penales diferentes.

Estos detalles descriptivos que se encuentran en cada redacción del tipo penal, son los que permiten distinguir entre uno y otro, lo cual es importantísimo, ya que como se observa las penas son sumamente diferentes, no es lo mismo, 10 a 13 años de pena privativa de libertad, que 22 a 26 años. Por eso, la redacción del tipo penal y la diferenciación por parte de quien lo lee, es fundamental. 


\subsection{Tipicidad subjetiva}

Una vez finalizado el estudio de la tipicidad objetiva, es menester realizar un estudio de la tipicidad subjetiva, la misma que como se dijo en líneas anteriores abarca el dolo y la culpa.

\subsubsection{Dolo}

Si se revisa el COIP antes de que entren en vigencia las reformas de diciembre del 2019, en su artículo 26 se contaba con una definición de dolo, que decía: "Actúa con dolo la persona que tiene el designio de causar daño" y esta definición era muy laxa e incompatible con el derecho penal contemporáneo. Es por eso que con la reforma al COIP, que se encuentran en vigencia a partir del 21 de junio del 2020, se cambia esta definición de dolo y se establece que: "Actúa con dolo la persona que conociendo los elementos objetivos del tipo penal, ejecuta voluntariamente la conducta" (COIP, 2014, art 26).

Con la definición actual de dolo establecida en la norma, se reafirma la presencia y adaptación del código a la dogmática penal finalista, reconociendo la teoría del delito y cada uno de sus peldaños (conducta, tipicidad, antijuridicidad y culpabilidad), y reafirmando las dos aristas más importantes para hablar de dolo, las cuales son: la existencia del elemento volitivo y cognitivo, es decir, el conocimiento y la voluntad por parte del sujeto activo al momento de actuar. El artículo 26 reformado del COIP hace referencia a los elementos objetivos del tipo que ya se trató anteriormente en la tipicidad objetiva, reafirmando una vez más su apego a la dogmática.

La reafirmación que hace el COIP respecto de la teoría finalista del delito del ilustre Hans Welzel se presencia al revisar la definición de dolo como: "Aquella voluntad finalista de acción que está dirigida hacia la concreción de las características objetivas de un tipo de injusto" (Welzel, 1956, p.43). Así también, Muñoz Conde ratifica la postura del COIP y señala que al dolo se lo debe entender como conciencia y voluntad (Muñoz Conde \& García 2010, p.267) de realizar y conocer los tipos objetivos que establece el tipo penal. Así mismo, es evidente 
que existen diferentes tipos de dolo como: dolo directo, indirecto y el tan tratado dolo eventual, pero eso será tema de otro ensayo.

\subsubsection{Culpa}

Para empezar a estudiar la culpa se debe revisar lo que establece el COIP en su artículo 27: "actúa con culpa la persona que infringe el deber objetivo de cuidado, que personalmente le corresponde, produciendo un resultado dañoso. Esta conducta es punible cuando se encuentra tipificada como infracción en este Código." (COIP, 2014).

Los delitos culposos o imprudentes como también los denomina la doctrina, son aquellos en los cuáles una persona por falta de previsibilidad, cuidado o incorrecto uso del medio para la realización de cierta conducta, genera un resultado material típico que produce un daño a cierto bien jurídico protegido. Por lo tanto, Muñoz Conde (2010) indica que la observancia del deber objetivo de cuidado o también conocido como "diligencia debida" (p.282), constituye el punto referencial del tipo penal imprudente.

El concepto de deber objetivo de cuidado es objetivo y normativo, pues, no existe como tal una definición marcada, ya que como se conoce en el COIP y en la mayoría de la normativa penal del resto de países en el mundo predominan los delitos dolosos, aquellos en los cuales la conducta que necesita realizar una persona para que se subsuma en el tipo penal es clara y se conoce; mientras que en los delitos culposos o imprudentes, son aquellos realizados "sin la intención", por ende, son producto de la falta de cuidado de una persona y no sería posible establecer una definición de una conducta culposa como tal.

El jurista español Muñoz Conde (2010) señala que:

Es objetivo, por cuanto no interesa para establecerlo cuál es el cuidado que en el caso concreto ha aplicado o podía aplicar el autor, sino cuál es el cuidado requerido en la vida de relación social respecto a la realización de una conducta determinada. Ello supone además un juicio normativo que surge de la comparación entre la conducta que hubiera seguido 
un hombre razonable y prudente en la situación del autor y la observada por el autor realmente. (p.285).

Un ejemplo muy común de delitos culposos son los delitos de tránsito, pues en teoría nadie sale a conducit un vehículo con la intención de matar personas, a no ser que se lo predisponga, de lo contrario no, a continuación un ejemplo breve:

Ejemplo E: Carlos, un padre de familia responsable y trabajador, decide proponer a su familia realizar un viaje a la playa para relajarse, planeando salir a la playa en su vehículo el día sábado en horas de la madrugada. Llega el día sábado y siendo las 2 a.m. Carlos y su familia suben las maletas y emprenden su viaje rumbo a la playa. En el camino, al tomar una curva normal las llantas del vehículo resbalan de la calzada, por lo que, el carro cae 25 metros al vacío y posterior falleciendo su esposa e hijos, mientras que Carlos es el único sobreviviente. Pregunta: ¿Responde Carlos por homicidio culposo? Sí, ¿por qué? Porque Carlos como conductor designado tenía un deber objetivo de cuidado, el cual era verificar que todas las partes del automotor estén en perfectas condiciones, lo cual no lo realizó. Ahora, supongamos que sí, lo hacía y verificaba que las llantas de su vehículo estaban en malas condiciones. Él hubiese tenido la oportunidad de cambiar los neumáticos y dicho accidente no se hubiese producido, entonces, es por falta de diligencia debida, que responde por homicidio culposo de su familia.

\subsubsection{Error de tipo}

La tipificación del error de tipo en el COIP, es otra de las novedades importantes de la reforma de diciembre del año pasado, en vista de que era una discusión sobre si era posible o no, aplicar error de tipo en el Ecuador. Y pues efectivamente por criterios dogmáticos y prácticos era totalmente aplicable, así no esté plasmado en la ley, es por eso que, ahora el COIP en su artículo 28.1 establece qué es y cuando una persona actuá en error de tipo, aquí su definición: 
Art 28.1. - Error de tipo. - No existe infracción penal cuando, por error o ignorancia invencibles debidamente comprobados, se desconocen uno o varios de los elementos objetivos del tipo penal.

Si el error es vencible, la infracción persiste y responde por la modalidad culposa del tipo penal, si aquella existe.

El error invencible que recae sobre una circunstancia agravante o sobre un hecho que califique la infracción, impide la apreciación de esta por parte de las juezas y jueces. (COIP, 2014).

La definición como tal del código sobre el error de tipo (Tatbestandsirrtum), deja dos puntos que analizar: i) ¿Cúando una persona cae en error o ignorancia? y ii) ¿A qué se refiere cuando dice debidamente comprobados? En el primer punto claramente dice que, esta persona desconoce uno o varios elementos objetivos del tipo, que ya se estudió anteriormente al hablar de tipicidad objetiva, pero en todos casos, error significa tener un conocimiento equívoco (Welzel, 1956, p.82) o ignorancia sobre cierto tema o cosa. Entonces, un ejemplo simple sería, cuando una persona destruye una cosa ajena en la creencia de que era suya, en ese supuesto estaríamos frente a un error de tipo referente al objeto material.

Otro término que establece el artículo 28.1 del COIP, es "debidamente comprobados". Como se conoce siempre el "onus probandi" le corresponde a la fiscalía, pero, en el caso de que se alegue error de tipo, se invierte la carga de la prueba, es decir, la persona que alega esta institución jurídica le corresponde por obligación el deber de probarlo, caso contrario no será válida la teoría del error de tipo alegada por una parte procesal.

\section{Antijuridicidad}

Una vez que se comprueba que una conducta es típica, se debe verificar si la misma es antijurídica, puesto que el concepto de antijuridicidad es importantísimo en la teoría del delito, pues, si una conducta es típica pero no antijurídica, se estaría frente a una conducta no 
delictiva; mientras que, si se tiene una conducta típica y además antijurídica, se puede seguir con el análisis de la misma para verificar si es objeto de una consecuencia jurídica (pena).

El artículo 29 referente a la antijuridicidad indica claramente que "Para que la conducta penalmente relevante sea antijurídica deberá amenazar o lesionar, sin justa causa, un bien jurídico protegido por este Código." (COIP, 2014). La norma claramente establece que, esta conducta típica para que sea contraria a Derecho, debe lesionar o amenazar un bien jurídico, que como se vio anteriormente es un derecho fundamental sujeto de valoración y de máxima protección. Ahora, también señala que se debe cometer una conducta sin justa causa, es decir, que si la conducta empleada por una persona está justificada por el Derecho, no es objeto de sanción y por eso también se tiene presente en el código las causas de justificación que serán estudiadas más adelante.

El término antijuridicidad o también conocida como antijuricidad significa prima facie contrariedad con el Derecho, ir en contra del mismo, puesto que, toda conducta es adecuada a Derecho o contraria a él, no existe opción intermedia, no se puede hablar nunca de que una conducta es permitida y al mismo tiempo prohibida (tertiur non datur) (Rodríguez, 2019, p.368).

Antes de pasar a analizar las causas de justificación, se debe tener claro que existe antijuridicidad formal y material. La antijuridicidad formal, no es más que la subsunción de la conducta al tipo penal, es decir, que la conducta ejercida por el sujeto activo, se encuadre en lo que nos establece la norma penal; mientras que la antijuridicidad material, se refiere a que dicha conducta desarrollada por el sujeto activo, ponga en riesgo, lesione o amenace un bien jurídico protegido por el Código.

\subsection{Causas de justificación de la antijuridicidad}

Toda conducta típica ejercida por un sujeto, siempre y cuando se encuentre justificada por alguna de las causas de justificación que establece la norma, no será objeto de consecuencia jurídica y 
se considerará que su actuar se encuentra enmarcado conforme a Derecho. Es así, como el COIP establece las siguientes causas de exclusión de la antijuridicidad: i) legítima defensa; ii) estado de necesidad; y iii) cumplimiento del deber legal de la o el servidor de la Policía Nacional y de seguridad penitenciaria. Esta última añadida con las reformas del COIP.

El artículo 30 del COIP señala:

No existe infracción penal cuando la conducta típica se encuentra justificada por estado de necesidad o legítima defensa.

Tampoco existe infracción penal cuando se actúa en cumplimiento de una orden legítima y expresa de autoridad competente o de un deber legal, debidamente comprobados. (COIP, 2014).

\subsubsection{Legítima Defensa}

La presente causa de justificación se refiere al comportamiento empleado por una persona que está siendo objeto de una posible vulneración de un derecho propio o a su vez de un derecho ajeno, para poder repudiar el ataque antijurídico empleado por un individuo. El jurista Felipe Rodríguez lo define de la siguente manera:

La legítima defensa es la legalidad (jurídicidad) de repeler una agresión ilegítima, actual o inminente, para salvaguardar un bien jurídico propio o de un tercero, este es, defenderse de una agresión ilegal sin esperar que el Estado actúe porque, por la inmediatez y la urgencia, la reacción personal es la única alternativa. (Rodríguez, 2019).

La legítima defensa se da en un determinado espacio y tiempo, es decir, tiene esta característica de inmediata, inminente, lo cual no permite que el Estado, a través de la Policía Nacional, puedan neutralizar la acción ilegítima que está siendo ejecutada por una persona, es por eso, que la persona que está siendo agredida en ese momento, puede emplear determinada conducta típica que llega a 
ser considerada jurídica. El COIP en su artículo $33^{13}$ señala tres presupuestos que se deben cumplir de manera obligatoria para que se configura la legítima defensa y estos son:

\section{Agresión actual e ilegítima.}

2. Necesidad racional de la defensa.

3. Falta de provocación suficiente por parte de quien actúa en defensa del derecho.

Al analizar cada uno de estos puntos, en primer lugar una agresión actual e ilegítima, se está hablando de aquella temporalidad que refiere el Dr. Rodriguez, ese momento en el que se está frente a una agresión real y que de una u otra manera se debe ver la forma de poder contrarrestar con otra acción; ahora, en cuanto a la necesidad racional de defensa, se hace referencia a esa necesidad de actuar por parte del ciudadano que está siendo víctima de tal agresión actual, ya que por razones de temporalidad el Estado no puede actuar de inmediato. Siendo así, se debe tener claro no confundir la "racionalidad" con la "proporcionalidad".

Por último, la falta de provocación suficiente, requisito fundamental para poder hablar de legítima defensa, ya que si bien se habla de una acción realizada por un sujeto, esta debe ser entendida como esporádica, entonces, si el sujeto A, en primera instancia provoca al sujeto B para que lo agreda y luego A contrarresta esta acción y quiere argumentar legítima defensa sería inaceptable y por lo tanto la acción de A sería ilícita. Queda así claro la aplicación de la legítima defensa y cuando se puede alegar la misma.

13 COIP - Art 33. - Legítima Defensa. - Existe legítima defensa cuando la persona actúa en defensa de cualquier derecho, propio o ajeno, siempre y cuando concurran los siguientes requisitos: 1 . Agresión actual e ilegítima; 2. Necesidad racional de la defensa; y 3. Falta de provocación suficiente por parte de quien actúa en defensa del derecho. 


\subsubsection{Estado de necesidad (justificante)}

Así como la legítima defensa, el COIP establece una segunda causa de justificación de la antijuridicidad, esta es, el estado de necesidad, el cual debe ser entendido como una vulneración de un derecho menor para la defensa de uno mayor. Al momento que se hace mención de un derecho menor y otro mayor, se está refiriendo a la existencia de una ponderación de derechos, de bienes jurídicos protegidos por el ordenamiento jurídico, pues evidentemente, si se plantea el supuesto de defender la vida o la propiedad, en el $100 \%$ de los casos se va a defender la vida.

Por ello, Mir Puig Santiago (2016) sostiene que el estado de necesidad es un estado de peligro actual para legítimos intereses que únicamente puede conjurarse mediante la lesión de intereses legítimos ajenos y que no da lugar a la legítima defensa ni al ejercicio de un deber (p.462), excluyendo de su concepto cualquier aplicación de otra causal de justificación y centrándose específicamente en el estado de necesidad como tal.

De igual forma el COIP en su artículo $32^{14}$ establece cuando una persona actúa en estado de necesidad y que requisitos fundamentales debe cumplir para que se pueda configurar esta causa de justificación, los requisitos que establece la norma son:

1. Que el derecho protegido esté en real y actual peligro;

2. Que el resultado del acto de protección no sea mayor que la lesión o daño que se quiso evitar; y

3. Que no haya otro medio practicable y menos perjudicial para defender el derecho.

14 COIP - Art 32. - Estado de necesidad. - Existe estado de necesidad cuando la persona, al proteger un derecho propio o ajeno, cause lesión o daño a otra, siempre y cuando se reúnan todos los siguientes requisitos: 1. Que el derecho protegido esté en real y actual peligro; 2. Que el resultado del acto de protección no sea mayor que la lesión o daño que se quiso evitar; y 3. Que no haya otro medio practicable y menos perjudicial para defender el derecho. 
Al igual que se analizó los requisitos necesarios de la legítima defensa, también se tiene que estudiar los requisitos para el cumplimiento del estado de necesidad según la norma, y en primer lugar se tiene que el derecho esté en real y actual peligro, esto quiere decir que, el derecho que está siendo objeto de protección se encuentre en una situación comprobable realmente de peligro, así como también, se habla de una temporalidad, el peligro debe ser en ese instante. Ahora, en cuanto al segundo requisito aquí cabe lo que se dijo en líneas anteriores, la ponderación de derechos.

El derecho que se pretende lesionar para proteger otro, no debe ser mayor realizando así una valoración objetiva de los mismos. Por último, se tiene la característica de que no debe existir otro medio practicable, caso contrario no sería válida la aplicación de un estado de necesidad, para lo cual, el juzgador analizará si en verdad no existían otros medios o formas de poder solventar ese peligro del derecho.

\subsubsection{Cumplimiento del deber legal}

Con el advenimiento de la reforma de diciembre del 2019, se implemente en el COIP el artículo 30.15, esta nueva causa de justificación

15 COIP - Art 30.1. - Cumplimiento del deber legal de la o el servidor de la Policía Nacional y de seguridad penitenciaria. - Existe cumplimiento del deber legal cuando una o un servidor de la Policía Nacional y de seguridad penitenciaria, al amparo de su misión constitucional, en protección de un derecho propio o ajeno, cause lesión, daño o muerte a otra persona, siempre y cuando se reúnan todos los siguientes requisitos: 1. Que se realice en actos de servicio o como consecuencia del mismo; 2. Que para el cumplimiento de su misión constitucional, dentro de su procedimiento profesional, observe el uso progresivo, proporcional y racional de la fuerza; y, 3. Que exista amenaza o riesgo inminente a la vida de terceros o a la suya propia o para proteger un bien jurídico. Por acto de servicio se entienden las actuaciones previas, simultáneas y posteriores, ejecutadas por la o el servidor en cumplimiento de su misión constitucional y el deber legal encomendado, inclusive el desplazamiento del servidor o servidora desde su domicilio hasta su lugar de trabajo y viceversa. También se considera acto de servicio, cuando la actuación 
denominada "Cumplimiento del deber legal de la e el servidor de la Policía Nacional y de seguridad penitenciaria”, mismo que surge a raíz del famoso caso de femicidio sucedido en la ciudad de Ibarra en el mes de enero, en el cual por negligencia e impericia al momento de actuar por parte de la Policía Nacional, una joven falleció tras recibir varias puñaladas en el abdomen.

Con la implementación de esta causa de justificación, se busca regular el actuar por parte de los servidores de la Policía y de seguridad penitenciaria, frente a situaciones de inminente peligro ya sea propio o de terceros, y de esta manera, evitar más casos como el mencionado anteriormente para lo cual corresponde analizar cada uno de los numerales que establece el artículo 30.1 del COIP:

1. Que se realice en actos de servicio o como consecuencia del mismo;

2. Que para el cumplimiento de su misión constitucional, dentro de su procedimiento profesional, observe el uso progresivo, proporcional y racional de la fuerza; $y$

3. Que exista amenaza o riesgo inminente a la vida de terceros o a la suya propia o para proteger un bien jurídico.

El primer numeral limita de cierta manera el actuar por parte de los serdiores policiales, puesto que restringe su accionar solamente al momento que estén prestando su servicio o a su vez surja del mismo, entonces, aquí queda la duda de ¿Qué pasaría si un servidor de la policía el día que se encuentra franco (día libre) y se encuentre viajando en un bus público, puede o no repeler una acción delictiva que se suscite ahí, como por ejemplo, un robo a mano armada?.

del servidor o servidora se realiza fuera del horario de trabajo, en cumplimiento de su misión constitucional, observando el riesgo latente, eficacia de la acción y urgencia de protección del bien jurídico. 
En cuanto al segundo numeral, se habla sobre el uso progresivo, proporcional y racional de la fuerza, es decir, el agente de la policía nacional debe observar estos criterios antes de actuar, esto con la finalidad de regular y limitar de igual forma el actuar excesivo por parte del servidor. Por último, el tercer numeral habla sobre un riesgo inminente, es decir, que la actuación ilegítima por parte del sujeto activo se vaya a materializar con seguridad, no una mera especulación infundada.

Para finalizar la presente categoría dogmática, es menester hablar sobre el exceso de las causas de exclusión de la antijuridicidad que establece el COIP en su artículo $31^{16}$, y pues bien, se ha venido diciendo que la persona que actúe en defensa de un derecho propio o ajeno debe actuar con racionalidad, proporcionalidad y progresividad, pues en caso de excederse ya no será aplicable una causa de justificación de la antijuridicidad y además se le impondrá el tercio de la mínima pena que establezca el tipo penal en el que haya subsumido su conducta.

\section{Culpabilidad}

Después de estudiar las anteriores categorías dogmáticas del delito se llegado al último peldaño de la misma, esto es la culpabilidad. Después de analizar la conducta típica y además antijurídica corresponde situarse y detenerse a estudiar este peldaño dogmático, el cual es sumamente importante, porque se abordan temas como la imputabilidad o ininputabilidad del sujeto activo, las causas de exculpación, y también el error de prohibición.

La culpabilidad como tal es ese reproche que realiza el juzgador al sujeto activo, puesto que dentro de sus capacidades cognitivas este tenía dos opciones: i) actuar conforme a Derecho y ii) actuar en contra de Derecho, es por eso, que se reprocha al sujeto su accionar

16 COIP - Art 31. - Causas de exclusión de la antijuridicidad. - La persona que se exceda de los límites de las causas de exclusión será sancionada con una pena reducida en un tercio de la mínima prevista en el respectivo tipo penal. 
siempre que por su libre albedrío decidió no acomodar su conducta conforme lo establece el ordenamiento jurídico.

García Falconí (2014) citado en Rodríguez (2019) señala que:

El principio de culpabilidad es el presupuesto subjetivo decisivo de la responsabilidad penal, pues la pena sólo puede fundamentarse tras la comprobación de que al autor se le pueda reprochar la formación de la voluntad que le condujo a la resolución delictiva.

\subsection{Imputabilidad e inimputabilidad}

En la parte general del COIP, específicamente en el artículo 34 se encuentra la culpabilidad, en la cual se establece que para que una persona pueda ser responsable, debe ser imputable. Entonces, surge la siguiente pregunta: ¿̨Cuándo una persona es imputable y cuándo no? Precisamente eso se va a analizar en los siguientes párrafos (Mir Puig, 2016, p.583).

Se debe definir a la imputabilidad en función de la normalidad motivacional del sujeto al momento de actuar, es decir, una persona es imputable cuando se encuentra en sus plenas capacidades psicológicas, teniendo plena capacidad de entender y comprender la norma, teniendo así, plena idoneidad para responder por la conducta típica y antijurídica que realizó, caso contrario, si carece de las mismas no puede haber culpabilidad.

Respecto a la inimputabilidad de un sujeto activo, el Código Orgánico Integral Penal establece dos supuestos para saber cuándo una persona es inimputable absolutamente, para lo cual, corresponde citar el artículo 35 del COIP, que dice: "No existe responsabilidad penal en los casos de error de prohibición invencible y trastorno mental, debidamente comprobados." (COIP, 2014). Solamente en los casos que plantea el código, serán completamente inimputables estas personas, puesto que si, se revisa más adelante se establece la responsabilidad por embriaguez o intoxicación y los menores de 18 años. En el caso de los menores de 18 años la inimputabilidad es relativa, puesto que para el caso existen, medidas socio educativas. 


\subsubsection{Transtorno mental}

Referente a la inimputabilidad de un sujeto por transtorno mental, se debe empezar citando al COIP:

Art. 36.- Trastorno mental.- La persona que al momento de cometer la infracción no tiene la capacidad de comprender la ilicitud de su conducta o de determinarse de conformidad con esta comprensión, en razón del padecimiento de un trastorno mental, no será penalmente responsable. En estos casos la o el juzgador dictará una medida de seguridad. (COIP, 2014).

Claramente, señala que el sujeto no puede comprender la ilicitud de su conducta, es decir, existe un déficit de capacidad intelectual o de comprensión, ya que el trastorno mental, se da por diferentes circunstancias, es por ello, que una persona fuera de sus cabales y que no entienda las consecuencias de sus actos, no debe ser objeto de consecuencia jurídica. Eso sí, claramente dice la norma, debidamente comprobados, que significa que se invierte la carga de la prueba.

\subsubsection{Responsabilidad por embriaguez o intoxicación}

El Código Orgánico Integral Penal en su artículo 37 establece:

Art. 37.- Responsabilidad en embriaguez o intoxicación.- Salvo en los delitos de tránsito, la persona que al momento de cometer la infracción se encuentre bajo los efectos del alcohol o de sustancias estupefacientes, psicotrópicas o preparados que las contengan, será sancionada conforme con las siguientes reglas:

1. Si deriva de caso fortuito y priva del conocimiento al autor en el momento en que comete el acto, no hay responsabilidad.

2. Si deriva de caso fortuito y no es completa, pero disminuye considerablemente el conocimiento, hay responsabilidad atenuada imponiendo el mínimo de la pena prevista en el tipo penal, reducida en un tercio.

3. Si no deriva de caso fortuito, ni excluye, ni atenúa, ni agrava la responsabilidad. 
4. Si es premeditada con el fin de cometer la infracción o de preparar una disculpa, siempre es agravante. (COIP, 2014).

Para empezar, el presente artículo en su parte inicial establece una excepción, ésta es en los deiltos de tránsito, pues en aquellos si una persona se encuentra bajo efectos del alcohol o de alguna sustancia catalogada sujeta a fiscalización, se considerará como agravante al momento de establecer una pena.

Cuando una persona realice una conducta típica y antijurídica, pero a su vez se encuentra bajo efectos de alcohol o de sustancias catalogadas sujetas a fiscalización o preparados que las contengan y los mismos priven de su capacidad de consentimiento, no será responsable penalmente. Ahora, si es una disminución leve de su capacidad cognitiva, si responderá con el mínimo de la pena reducida en un tercio, entonces como conclusión, se tiene una inimputabilidad relativa.

Para finalizar, este estado de intoxicación y por ende privación de la capacidad de entendimiento no debe ser auto provocado por parte del sujeto que realiza la acción material típica, pues en ese caso, esta persona estaría actuando con el conocimiento y la voluntad de querer realizar cierta conducta ílicta.

\subsubsection{Personas menores de 18 años}

Como se dijo anteriormente, los menores de edad son inimputables penalmente, pero ésta inimputabilidad es relativa, puesto que, pese a no ajustarse a una sanción establecida por el COIP, si son aplicables medidas socioeducativas establecidas en el Código Orgánico de la Niñez y Adolescencia (CONA).

Para poder entender el párrafo anterior se debe citar dos artículos del COIP, en primer lugar el artículo 38 que dice:

Art. 38.- Personas menores de dieciocho años.- Las personas menores de dieciocho años en conflicto con la ley penal, estarán sometidas al Código Orgánico de la Niñez y Adolescencia. (COIP, 2014). 
Aquí la pregunta que surge es: ¿No se supone que sólo se pueden aplicar las sanciones que establezca el Código Orgánico Integral Penal? Y para poder dar respuesta a la misma, se debe citar el segundo artículo que anteriormente se mencionó, es decir, el artículo 17 del COIP, que establece:

Art. 17.- Ámbito material de la ley penal.- Se considerarán exclusivamente como infracciones penales las tipificadas en este Código. Las acciones u omisiones punibles, las penas o procedimientos penales previstos en otras normas jurídicas no tendrán validez jurídica alguna, salvo en materia de niñez y adolescencia, y en materia de usuarios y consumidores. (COIP, 2014).

Como se puede observar en la parte final que se encuentra con negrita, existe una salvedad, que es excepto en materia de niñez y adolescencia. A través del artículo citado anteriormente, las medidas disciplinarias correctivas que sean impuestas a través del CONA, tendrán plena validez. Estas medidas socio educativas que dispone el CONA, tendrán como finalidad la correción del menor, la rehabilitación y la inserción en la sociedad, para lo cual, es de vital importancia la colaboración de la familia.

\subsection{Error de prohibición}

El error de prohibición es el desconocimiento de la antijuridicidad de la conducta, o erróneo entender de que el actuar propio se encuentra permitido por una causa de exculpación de la antijuridicidad que nos permite actuar de esa manera. Es desconocer que la conducta está prohibida o creerse asistido por una causa de justificación, de igual manera, cuando se alegue error de prohibición para ausentar de culpabilidad a un sujeto, le corresponderá probar en cada caso concreto (Zaffaroni, 1998, p.471). Así también, en la doctrina se sostiene que quien actúa en error de prohibición posee una falsa concepción del Derecho (Roxin, 1994, p.584) y producto de aquello se puede eximir de culpabilidad a una persona.

Dentro de la misma se tiene el error de prohibición directo e indirecto, que se estudiará a continuación, no sin antes citar el artículo 35.1 del COIP, vigente desde la reforma de diciembre. 
Art. 35.1.- Error de prohibición.- Existe error de prohibición cuando la persona, por error o ignorancia invencible, no puede prever la ilicitud de la conducta.

Si el error es invencible no hay responsabilidad penal.

Si el error es vencible se aplica la pena mínima prevista para la infracción, reducida en un tercio.

Claramente la norma establece dos supuestos, el primero en caso de que el error se torne invencible, donde no existiría responsabilidad penal para el sujeto activo que ejerza la conducta; mientras que, en el caso de ser un error vencible, se le aplicará el mínimo de la pena, reducida en un tercio. Corresponde estudiar más a fondo esta institución jurídica, revisando lo que establece la doctrina acerca de estos supuestos.

\subsubsection{Error de prohibición directo}

El error es directo cuando se tiene una falsa o equivocada percepción de la realidad, basada en tres hipótesis: i) Existencia de un tipo penal; ii) Vigencia del tipo penal; y iii) Sentido o alcance de la prohibición. En el primer supuesto, se hace referencia a cuando en un Estado existe una prohibición de realizar ciertas conductas, por ejemplo: talar árboles y un turista recién llegado de otro país tala un árbol con la finalidad de realizar una fogata, es decir, existía una prohibición expresa pero el sujeto por desconocimiento absoluto no pudo preveerla.

El segundo supuesto refiere a un falso o erróneo conocimiento de la norma por parte de una persona, ahora, habrán personas que digan que "el desconocimiento de la norma, no exime de responsabilidad", pero se debe tener en cuenta que este es un concepto relativo, no absoluto. Por último, en relación al sentido o alcance de la norma y para entender este supuesto, a continuación un ejemplo referente al cannabis. 
Ejemplo F: Un ciudadano uruguayo, tiene en su país el respectivo carné de consumidor y demás permisos para portar marihuana, recordemos que en dicho país es legal, por lo que, un día emprende un viaje con un amigo y llegan a Ecuador. En la frontera, agentes de la Policía, proceden a realizar un control de rutina y encuentran marihuana. El ciudadano uruguayo presenta sus permisos para portar dicha sustancia, creyendo erróneamente que con dicho carné podía transitar libremente. Es ahí cuando este ciudadano estaría actuando en un error de prohibición respecto al sentido o alcance de la norma, pues tenía un correcto entendimiento sobre la misma, ya que por su recién llegada al Ecuador, le era imposible saber si era o no permitido aquí, recordemos una vez más, que todo debe ser debidamente comprobado por quien lo alega.

\subsubsection{Error de prohibición indirecto}

El error de prohibición indirecto es cuando existe una creencia equivocada de que no se está realizando un comportamiento antijurídico, así también, se da por un falso juicio sobre la concurrencia de una causa de exclusión de la antijuridicidad, respecto a este falso juicio sobre la aplicación de una causa de justificación, se tiene cuatro hipótesis que son:

1. Cuando la persona percibe equivocadamente los hechos. Es decir, no entiende lo que pasa y asume de manera errada que concurren los requisitos fácticos de una causa de justificación, un breve ejemplo: Una persona con un grado de paranoia leve, acuchilla a un niño que le apunta con una pistola de juguete, pensando que es de verdad.

2. Cuando la persona incurre en un error de valoración jurídica, no fáctica, sobre los supuestos de una causal de exclusión de la antijuridicidad, es decir, cree que los requisitos de la legítima defensa son otros, a los establecidos en la norma.

3. Cuando la persona actúa bajo la convicción de que concurren los supuestos fácticos de una causal de exclusión de la culpabilidad.

4. Cuando la persona incurre en un error de valoración sobre los supuestos jurídicos de una causal excluyente de la culpabilidad. 
Finalmente, la tipificación del error de prohibición en el COIP, fue un avance jurídico en el Ecuador, pues así, se terminaron esas pequeñas discrepancias sobre si era o no aplicable el error de prohibición, por el hecho de no encontrarse establecido de manera escrita en la norma penal.

\section{Conclusiones}

A modo de conclusión del presente trabajo analítico sobre el estudio de la teoría del delito en el Código Orgánico Integral Penal, se debe tener en claro los siguientes puntos importantísimos que se han desarrollado a lo largo del mismo:

1. A través de la lectura detenida de la parte general y especial del COIP, se puede denotar evidentemente la presencia y el apego que tiene el presente cuerpo normativo a la escuela finalista del maestro Hans Welzel, en tanto y cuanto que dentro de la parte general señala el estricto cumplimiento de todas las categorías dogmáticas del delito (conducta, tipicidad, antijuridicidad y culpabilidad) para poder hablar de una conducta penalmente relevante y que la misma es objeto de consecuencia jurídica para cierta persona.

2. El conocimiento integro de dogmática penal por parte de jueces, fiscales y abogados defensores públicos o privados es de vital importancia dentro de la esfera del litigio profesional, pues como se comprobó, existen cuestiones técnicas dentro de cada categoría dogmática del delito que pueden coadyuvar a plantear una teoría del caso con resultado positivo para la defensa del procesado, o a su vez, para en el caso de la fiscalía para comprobar la culpabilidad del mismo. 


\section{Referencias Bibliográficas}

Agudelo, N. (2004). Curso de Derecho Penal, Esquemas del Delito, Tercera edición. Bogotá - Colombia: Ed. Temis S.A.

Código Orgánico Integral Penal [COIP]. (2014). Registro Oficial No. 107 (24-diciembre-2019) Suplemento.

Mir Puig, S. (2016). Derecho Penal, Parte General, 10ma edición, actualizada y revisada. Barcelona - España: Ed Reppertor.

Muñoz Conde, F., \& García, M. (2010). Derecho Penal, Parte General, 8va edición, revisada y puesta al día. Valencia - España.

Peña Gonzáles, O., \& Almanza Altamirano, F. (2010). Teoría del Delito, Manual Práctico para su aplicación en la teoría del caso. Lima - Perú: Editorial Nomos \& Thesis E.I.R.L.

Navarrete, M. (2019). Lecciones de Derecho Penal Parte General Tomo II. En F. Rodríguez Moreno, Curso de Derecho Penal Parte General Tomo II Teoría del Delito. Quito - Ecuador: Cevallos Editora Jurídica.

Rodríguez, F. (2019). Curso de Derecho Penal Parte General Tomo II Teoría del Delito. Quito - Ecuador: Cevallos Editora Jurídica.

Roxin, C. (1994). Derecho Penal, Parte General, Fundamentos de la estructura de la teoría del delito Tomo I. Munchen - Alemania: Ed. Civitas.

Welzel, H. (1956). Derecho Penal, Parte General, Traducido por Carlos Fontán Balestra. Buenos Aires - Argentina: Roque Depalma.

Zaffaroni, E. (1998). Tratado de Derecho Penal, Parte General, Tomo I. Buenos Aires - Argentina: Ed. Ediar. 